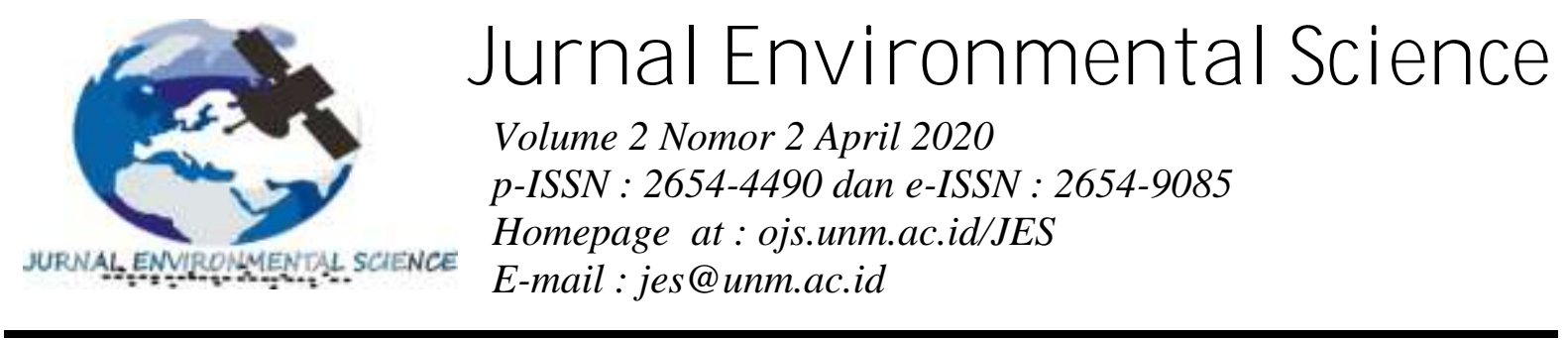

\title{
PEMETAAN LOKASI RAWAN KECELAKAAN SEPANJANG JALAN BONE-WAJO AXIS DI KABUPATEN BONE
}

\author{
Muhammad Zakir ${ }^{1}$ \\ Jurusan Geografi, Fakultas Matematika dan Ilmu Pengetahuan Alam, \\ Universitas Negeri Makassar, Indonesia. \\ Email: zakir.muhammad.geo@gmail.com ${ }^{l}$
}

\begin{abstract}
ABSTRACK
The purpose of this study is (1) To find out which areas often experience accidents, (2) To find out what factors influence so that accidents often occur in these areas (3) To find out the characteristics of roads that often experience accidents. The object of this study is road axis Bone - Wajo Bone district. Primary data used include road geometry, traffic signs and accident prone locations. Secondary data used include spatial data, data on the number of accidents and road condition data in Bone district. The data analysis used is Quantitative Descriptive and the analytical method used is the Cusum analysis method to identify accident prone points. The results of the study show there are seven regions classified as prone on the Bone - Wajo axis road, six of them have accident prone criteria (very low) and one is high, while the characteristics that influence it include land use, road slope traffic signs, and road geometry.
\end{abstract}

Keywords: accident-prone locations, Bone distric

\begin{abstract}
ABSTRAK
Tujuan penelitian ini adalah (1)Untuk mengetahui wilayah mana saja yang sering mengalami kecelakaan.(2)Untuk mengetahui faktor apa saja yang mempengaruhi sehingga sering terjadi kecelakaan di daerah tersebut(3) Untuk mengetahui karakteristik jalan yang sering mengalami kecelakaan.Objek penelitian ini yaitu jalan poros Bone - Wajo kabupaten Bone .Data primer yang di gunakan meliputi geometri jalan, rambu - rambu lalulintas, dan lokasi titik rawan kecelakaan .Data sekunder yang di gunakan meliputi data spasial,data jumlah kecelakaan dan data kondisi jalan di kabupaten Bone.Analisis data yang digunakan adalah Deskriktif Kuantitatif dan metode analisis yang di gunakan yaitu metode analisis cusum untuk mengidentifikasi titik rawan kecelakaan.Hasil penelitian menunjukkan terdapat tujuh wilayah tergolong rawan di jalan poros Bone - Wajo enam diantaranya memiliki kriteria rawan kecelakaan (sangat rendah) dan satu tergolong tinggi adapun karakteristik yang mempengaruhinya antara lain penggunaan lahan, rambu lalu lintas kemiringan medan jalan, dan geometri jalan .
\end{abstract}

Kata Kunci :Lokasi Rawan Kecelakaan,Kabupaten Bone 


\section{PENDAHULUAN}

Kecelakaan lalu lintas adalah kejadian di mana sebuah kendaraan bermotor atau mobil tabrakan dengan benda lain dan menyebabkan kerusakan .Kadang kecelakaan lalu lintas ini dapat mengakibatkan luka-luka atau kematian pada manusia atau binatang. Kecelakaan lalu lintas menelan korban jiwa sekitar 1,2 juta manusia setiap tahun(WHO,2004).

Untuk di Indonesia sendiri tingkat penggunaan trasportasi bertambah Setiap tahunnya. Baik itu roda dua maupun kendaraan roda empat.Kepadatan kendaraaan yang terus meningkat setiap tahunya ini menyebabkan permasalahan lalu lintas diantaranya sering terjadi kecelakaan lalu lintas di jalan yang ada di Indonesia yang jumlahnya juga meningkat setiap tahunnya.(BPS,2017)

Jalan poros Bone-wajo adalah jalan provinsi yang merupakan jalan kolektor dalam sistem jaringan primer yang menghubungkan ibukota provinsi dengan ibu kota kabupaten/kota ,dan jalannya strategis provinsi. Dan di jalan ini tingkat kepadatan kendaraannya cederung tinggi karena akses kendaraan dari kabupaten dan kota menggunakan jalan ini. Sehingga tingkat kecelakaannya juga cenderung tinggi penyebabnya kebanyakan di karena kan banyaknya hewan peliharaan masyarakat yang lalu lalang di jalan raya seperti sapi,kambing dan anjing.seringnya terjadi banjir dan juga badan jalan yang beresebelahan dengan sungai mengakibatkan banyaknya jalan yang rusak seperti lonsor karena tererosi oleh air sungai, berlubang,bergelombang serta aspal yang sudah terkelupas yang di akibatkan dari banjir.(Polsek Uloe,2018)

Melihat banyaknya kecelakaan yang terjadi dan meningkat dari tahun ketahun di Indonesia pada umumnya dan pada jalan poros Bone-Wajo Kabupaten Bone pada khususnya.saya berinisiatif untuk membuat peneliatian ini supaya bisa meminimalisir terjadinya kecelakaan di wilayah ini karena dengan adanya peta lokasi rawan kecelakaan di sepanjang jalan poros Bone-Wajo Kabupaten Bone ini.maka saya berharap masyarakat akan lebih berhati-hati di lokasi yang sering terjadi kecelakaan diwilayah ini.

\section{METODE}

Untuk objek penelitian mengambil tempat di sepanjang jalan poros Bone-Wajo Kabupaten Bone. Metode penelitian yang di pakai di penelilitian ini yaitu deskriptif untuk mencari, menemukan, dan mendeskriptifkan serta melihat keterkaitan objek antara variabel yang lebih di tekankan secara kualitatif,yaitu faktor-faktor yang berpengaruh terhadap kecelakaan lalu lintas di kabupaten Bone yang hasilnya berbentuk peta lokasi rawan kecelakaan di sepanjang jalan poros Bone-Wajo. adapun data primer yang di gunakan di penelitian ini adalah sebagai berikut: Penentuan absolute (Koordinat $\mathrm{X}$ dan Y)lokasi rawan kecelakaan dan titik rawan kecelakaan ,Rambu-Rambu Lalu Lintas ,Penggunaan lahan ,Geometri jalan meliputi ,Lebar jalan dan median jalan.Untuk data sekundernya menggunakan Peta Jaringan Jalan.Peta Administrasi,Data Jumlah Kecelakaan ,Citra dari Image Google Art. Adapun populasi pada penelitian ini yakni sepanjang jalan poros Bone-Wajo.Lokasi ini di ambil karena rentannya kecelakaan di wilayah ini. Penentuan sampel di lakakukan dengan cara purposive sampling. Yaitu pengambilan sampel secara sengaja.

Untuk pelaksanaan penelitian menggunakan alat-alat dan bahan sebagai berikut: GPS(Global Positioning System), Kamera Digital , Perlengkapan Tulis Menulis dan Rol Meter. Untuk kegiatan Pengolahan Data :Laptop dan Printer. Untuk mendukung pelaksanaan penelitian ini,maka akan di lakukan metode pengumpulan data sebagai berikut :Studi literatur merupakan upaya untuk menjelajahi berbagai data dan informasi yang tertuang dalam buku, jurnal, laporan penelitian maupun informasi dari internet.Diskusi ahli merupakan upaya membahas data dan informasi yang di kemukakan oleh para ahli dengan latar belakang pengetahuan dan pengalaman dalam bidang geografi transportasi dan sistem informasi geografi.Dokumentasi yaitu pengumpulan data yang telah ada daari dinas terkait.data yang bisa di ambil misalkan nama jalan,sistem arus lalu lintas, lokasi rawan kecelakaan dan lain-lain.Observasi yaitu mengumpulkan data lansung dari lapangan .Observasi ini di lakukan apabila data yang di butuhkan tidak ada pada dinas yang bersangkutan. Wawancara yakni mendapatkan informasi dengan cara bertanya lansung kepada responden .Ini bertujuan untuk menjamin kebenaran data dan ke lengkapan data.

Analisis data merupakan merupakan analisis dari hasil observasi lapangan.Analisis penelitian ini,yaitu: Deskriptif kuantitatif .Kuantitatif yaitu mengetahui data tentang Jumlah Kecelakaan dalam suatu ruas jalan.Teknik Cusum (Cumulative Summary) adalah suatu prosedur yang dapat digunakan untuk mengidentifikasikan black spot.Grafik cusum merupakan suatu prosedur statistik standar 
sebagai kontrol kualitas untuk mendeteksi perubahan dari nilai mean. Nilai cusum dapat dicari dengan rumus (Austroad, 1992):

Perhitungan untuk mencari nilai mean dari data sekunder, yaitu sebagai berikut :

$$
\mathrm{W}=\frac{\sum X 1}{L \times T}
$$

Keterangan :

$W=$ Nilai mean

$\sum \mathrm{X} 1=$ Jumlah kecelakaan

$\mathrm{L}=$ Jumlah stasion

$\mathrm{T}=\mathrm{Waktu} /$ periode

Perhitungan untuk mencari nilai cusum kecelakaan tahun pertama adalah dengan mengurangi jumlah kecelakaan tiap tahun dengan nilai mean, yaitu:

$$
\begin{aligned}
& S_{1}=\left[S_{0}+\left(X_{1}-W\right)\right] \\
& \text { Keterangan : } \\
& S_{1}=\text { Nilai cusum kecelakaan } \\
& \text { So = Nilai cusum kecelakaan untuk tahun pertama } \\
& \mathrm{Xi}=\text { Jumlah kecelakaan tiap tahun } \\
& \mathrm{W}=\text { Nilai mean }
\end{aligned}
$$

Adapun Tabel 1 Klasifikasi dalam penentuan titik rawan kecelakaan (black spot)adalah sebagai berikut :

\begin{tabular}{lll} 
No & Nilai Cusum $\left(\boldsymbol{S}_{\mathbf{1}}\right)$ & Kriteria \\
\hline 1 & Memiliki nilai $(0)$, & Rawan kecelakaan \\
\hline 2 & Memiliki nilai $(-0)$, & Tidak rawan kecelakaan \\
\hline & \multicolumn{2}{c}{ Sumber: (Austroad,1992) }
\end{tabular}

Tingkatan kriteria nilai cusum pada titik rawan kecelakaan meliputi sangat tinggi yaitu antar 70 $>100$,tinggi, antara 50 - 69, sedang, antara 30 -49 rendah,antara 15 - 29 dan sangat rendah yaitu $0,1-$ 14. Pengelolahan, tahap ini meliputi analisis data angka kecelakaan ,analisis penentuan,lokasi rawan kecelakaan dan ploting data rawan kecelakaan kelam peta .Penelitian ini menghasilkan data pada daerah rawan kecelakaan.Dalam sebuah penelitian tahap ini merupakan tahap akhir penelitian, merupakan tahap laporan dan uraian pembahasan hasil penelitian.

\section{HASIL DAN PEMBAHASAN Hasil}

\section{Gambran Umum Lokasi Penelitian}

Kabupaten Bone merupakan salah satu kabupaten yang terletak di pesisir Timur Provinsi Sulawesi Selatan dan berjarak sekitar $225 \mathrm{~km}$ terhitung dari ujung utaranya ke kota Makassar. Luas wilayahnya sekitar $4.559 \mathrm{~km}^{2}$ atau 9,78 persen dari luas Provinsi Sulawesi Selatan. Kabupaten Bone mempunyai garis pantai sepanjang $138 \mathrm{~km}$. Wilayah yang besar ini terbagi menjadi 27 kecamatan dan 372 desa/kelurahan. Ibukota Kabupaten Bone adalah Watampone.

Secara geografis Kabupaten Bone berbatasan kabupaten wajo,soppeng di utara.Timur teluk Bone,Selatan kabupaten Sinjai dan di bagian barat berbatasan dengan kabupaten Maros,pangkep Dan Barru.Secara astronomis Kabupaten Bone terletak pada posisi $4^{\circ} 13^{\prime}-5^{\circ} 6^{\prime}$ Lintang Selatan dan antara $119^{\circ} 42^{\prime}-120^{\circ} 30^{\prime}$ Bujur Timur. Letaknya yang dekat dengan garis khatulistiwa menjadikan Kabupaten Bone beriklim tropis . Sepanjang tahun 2014, kelembaban udara berkisar antara 77-86 persen dengan suhu udara $24,4^{\circ} \mathrm{C}-27,6^{\circ} \mathrm{C}$. Dan untuk jalan poros Bone - Wajo sendiri terletak di $4^{\circ} 13^{\prime} 22^{\prime \prime}-120^{\circ} 7^{\prime} 51^{\prime \prime}$ Ls dan 4 ${ }^{\circ} 4^{\prime} 48^{\prime \prime}$ - $120^{\circ} 16^{\prime} 46^{\prime \prime}$ BT. Memanjang dari Kecamatan Ajangale di utara melewati kecematan Dua Boccoe,tellu siattinge ,Awangpone sampai kecamatan Tanete Riattang di ujung selatannya dengan panjang $70 \mathrm{~km}$. Pada tahun 2019 di bagian utara Bone ini 
sudah mengalami perbaikan di sebagian besar wilayahnya. Jadi wilayah yang tergolong rawan dulunya menjadi tidak rawan lagi di beberapa tempat. Berdasarkan hasil penelitian tahun 2019,di peroleh titik lokasi rawan kecelakaan lalulintas dari hasil identifikasi dilapangan serta pengelolahan data,Adapun titik rawan kecelakaan lalulintas pada daerah rawan kecelakaan di sepanjang jalan poros Bone- Wajo antara lain :

Jalan Poros Bone - Wajo membentang di di tiga kecamatan yakni kecamatan Ajangale,Dua Boccoe ,Awangpone jalan ini menghubungkan dengan pusat Kota Bone Dan Kabupaten Wajo.Adapun titk rawan kecelakaan di wilayah ini di mulai dari Kecamatan Ajangale 2 titik yaitu Pompanua kilometer 5 dan welado kilometer 15. Dan untuk Dua Boccoe terdapat 4 lokasi rawan keceleakaan yaitu kilometer 18 tawaroe,kilometer 23 kilometer 30 tono desa pattiro ,dan kilometer 35 desa pattiro dan di kecamatan Awangpone 1 lokasi yaitu kilometer 65 desa jaling lattekko.keterangan lebih lengkapnya dapat dilihat pada Tabel dibawah.

Tabel 2 Koordinat lokasi titik rawan Kecelakaan pada jalan Pros Bone - Wajo

\begin{tabular}{cccc}
\hline No & Nama Lokasi & \multicolumn{2}{c}{ Koordinat } \\
\cline { 3 - 4 } & & Lintang & Bujur \\
\hline 1. & Ruas jalan kilometer 5 & $4^{\circ} 13^{\prime} 20^{\prime \prime} \mathrm{S}$ & $120^{\circ} 7^{\prime} 51^{\prime \prime} . \mathrm{E}$ \\
\hline 2. & Ruas jalan kilometer 15 & $4^{\circ} 13^{\prime} 33^{\prime \prime} \mathrm{S}$ & $120^{\circ} 8^{\prime} 56^{\prime} . \mathrm{E}$ \\
\hline 3. & Ruas jalan kilometer 18 & $4^{\circ} 17^{\prime} 3^{\prime \prime} \mathrm{S}$ & $120^{\circ} 14^{\prime} 45^{\prime} . \mathrm{E}$ \\
\hline 4. & Ruas Jalan kilometer 23 & $4^{\circ} 18^{\prime} 7^{\prime \prime} \mathrm{S}$ & $120^{\circ} 14^{\prime} 48^{\prime \prime} . \mathrm{E}$ \\
\hline 5 & Ruas jalan kilometer 30 & $4^{\circ} 18^{\prime} 3^{\prime \prime} \mathrm{S}$ & $120^{\circ} 14^{\prime} 40^{\prime \prime} . \mathrm{E}$ \\
\hline 6. & Ruas jalan kilometer 35 & $4^{\circ} 19^{\prime} 6^{\prime \prime} \mathrm{S}$ & $120^{\circ} 14^{\prime} 59^{\prime \prime} . \mathrm{E}$ \\
\hline 7. & Ruas jalan Kilometer 65 & $4^{\circ} 24^{\prime} 48^{\prime \prime} \mathrm{S}$ & $120^{\circ} 16^{\prime} 46^{\prime \prime} . \mathrm{E}$ \\
\hline
\end{tabular}

Sumber: Hasil Analisis, 2019

\section{Pembahasan}

Berdasarkan analisis dari hasil penelitian dapat di ketahui bahwa ruas jalan yang teridentifikasi sebagai titik rawan kecelakaan lalulintas pada jalan poros bone - wajo kabupaten Bone meliputi (a) Ruas jalan kilometer 5 dengan Jumlah kecelakaan pada ruas jalan ini 34 kejadian. Ruas Kilometer memiliki kemiringan medan jalan datar ,dengan lebar jalan 6 meter.Ruas jalan kilometer 5 memilki nilai cusum sebesar 7,42 nilai tersebut merupakan nilai di atas rata - rata jumlah kejadian kecelakaan,sehngga daerah tersebut terindetifikasi sebagai titik rawan,(b)Ruas jalan kilometer 15 Jumlah kecelakaan di ruas jalan ini adalah 40 kecelakaan.ruas jalan kilometer 15 ini memiliki kemiringan medan jalan datar, dengan lebar jalan 8 meter.Ruas jalan kilometer 15 ini memiliki cusum 3,44 denga kriteria rawan kecelakaan (sangat rendah)memiliki nilai di atas rata - rata Jumlah kejadian kecelakaan sehingga daerah ini teridentifikasi rawan kecelakaan.(c)Ruas jalan kilometer 18 Jumlah kecelakaan di ruas jalan ini adalah 39 kecelakaan.ruas jalan kilometer 18 ini memiliki kemiringan medan jalan datar ,dengan lebar jalan 8 meter. Ruas jalan kilometer 18 ini memiliki cusum 9,44 dengan kriteria rawan kecelakaan (sangat rendah) memiliki nilai di atas rata - rata Jumlah kejadian kecelakaan sehingga daerah ini teridentifikasi rawan kecelakaan .(d) Ruas jalan kilometer 23 Jumlah kecelakaan di ruas jalan ini adalah 34 kecelakaan.ruas jalan kilometer 23 ini memiliki kemiringan medan jalan datar ,dengan lebar jalan 8 meter. Ruas jalan kilometer 23 ini memiliki nilai cusum 3,44 dengan kriteria rawan kecelakaan (sangat rendah) memiliki nilai di atas rata - rata Jumlah kejadian kecelakaan sehingga daerah ini teridentifikasi rawan kecelakaan.(e) Ruas jalan kilometer 30 Jumlah kecelakaan di ruas jalan ini adalah 33 kecelakaan.ruas jalan kilometer 30 ini memiliki kemiringan medan jalan datar ,dengan lebar jalan 8 meter.Ruas jalan kilometer 30 ini memiliki nilai cusum 8,86 dengan kriteria rawan kecelakaan (sangat rendah) memiliki nilai di atas rata - rata Jumlah kejadian kecelakaan sehingga daerah ini teridentifikasi rawan kecelakaan .(f)Ruas jalan Kilometer 35 Jumlah kecelakaan di ruas jalan ini adalah 32 kecelakaan.ruas jalan kilometer 35 ini memiliki kemiringan medan jalan datar, dengan lebar jalan 8 meter. Ruas jalan kilometer 35 ini memiliki nilai cusum 1,44 dengan kriteria rawan kecelakaan (sangat rendah) memiliki nilai di atas rata - rata Jumlah kejadian kecelakaan sehingga daerah ini teridentifikasi rawan kecelakaan.(g)Ruas jalan kilometer 65 Jumlah kecelakaan di ruas jalan ini adalah 66 kecelakaan.ruas jalan kilometer 65 ini memiliki kemiringan medan jalan datar, dengan lebar jalan 8 meter. Ruas jalan kilometer 65 ini memiliki nilai cusum 52,32 
dengan kriteria rawan kecelakaan (tinggi) memiliki nilai di atas rata - rata Jumlah kejadian kecelakaan sehingga daerah ini teridentifikasi rawan kecelakaan .

\section{SIMPULAN DAN SARAN}

Berdasarkan hasil penelitian tahun 2019, di peroleh titik lokasi kecelakaan lalulintas dari hasil identifikasi di lapangan serta pengolahan data, adapun titik rawan kecelakaan lalu lintas pada daerah rawan kecelakaan di kabupaten Bone atara lain : ruas jalan kilometer 5 yang terdapat di Pompanua kecamatan Ajangale ,ruas jalan kilometer 15 yang terdapat di desa welado kecamatan Ajangale,ruas jalan kilometer 18 yang terdapat di desa Tawaroe kecamatan Dua Boccoe,ruas jalan kilometer 23 yang terdapat di desa Tocina kecamatan Dua Boccoe,ruas jalan kilometer 30 yang terdapat di dusun Tono desa Pattiro kecamatan Dua Boccoe,dan ruas jalan kilometer 65 yang terdapat di dusun Lattekko desa Jaling Kecamatan Awangpone.

Penetuan lokasi titik rawan kecelakaan diambil dari hasil perhitungan analisis cusum kecelakaan berdasarkan hasil pengolahan data Polres Bone tahun 2016 -2018 dari data tersebut di dapat nilai mean .Dimana mean adalah jumlah kecelakaan di bagi jumlah stasiun di kali periode pada tiap jalan ,nilai mean cusum tahun pertama adalah jumlah jumlah kecelakaan tiapa tahun di bagi dengan mean pada tiap stasiun, dan nilai cusum tahun selanjutnya adalah nilai cusum tahun pertama di tambah jumlah kecelakaan di kurangi pada mean pada setiap stasiun.untuk mengetahui persimpangan bahwa persimpangan dan ruas jalan yang teridentifikasi sebagai titik rawan kecelakaan adalah dengan memiliki nilai cusum positif dengan kriteria kecelakaan meliputi sangat tinggi,sedang,sangat rendah dantidak rawan kecelakaan.Adapun ruas jalan tersebut meliputi ruas jalan kilometer 5 di Pompanua kriteria jalan rawan kecelakaan (sangat rendah) dengan nilai cusum 7,42, ruas jalan kilometer 15 di desa Welado dengan kriteria jalan rawan kecelakaan (sangat rendah) dengan nilai cusum 3,44, ruas jalan kilometer 18 di desa Tawaroe dengan kriteria jalan rawan kecelakaan (sangat rendah) nilai cusum 9,44,ruas jalan kilometer 23 desa tocina kriteria rawan kecelakaan (sangat rendah)nilai cusum 3,44 ,ruas jalan kilometer 30 Tono desa pattiro kriteria rawan kecelakaan (sangat rendah )nilai cusum 8,86 ,ruas jalan kilometer 35 desa pattiro kriteria rawan kecelakaan (sangat rendah) nilai cusum 1,44 ,dan terakhir ruas jalan kilometer 65 kriteria rawan kecelakaan (tinggi) nilai cusum 52,32.Karakteristik lokasi titik rawan kecelakaan lalulintas pada jalan poros Bone - Wajo kabupaten Bone yakni faktor kendaraan, kondisi jalan ,rambu-rambu lalulintas, penggunaan lahan Kabupaten Bone dan faktor manusia sebagai pemakai jalan .

\section{DAFTAR RUJUKAN}

Dwiyogo,P dan Prabowo,(2006), Studi Identifikasi Daerah Rawan Kecelakaan (Blackspot dan Blacksite) Pada Jalan Tol Jagorawi. Tugas Akhir,Jurusan Teknik Sipil, Universitas Diponegoro, Semarang.

Kartika ,Metta.2008. Studi Identifikasi Analisis Faktor Penyebab Kecelakaan Lalu Lintas Pada Pengendara Sepeda Motor Di Wilayah Depok (Menggunakan Data Kecelakaan Polres Metro Depok Tahun 2008). Jurusan Kesehatan dan Keselamatan Kerja, FKM,UI.

Warpani, S, 2002, Pengelolaan Lalu Lintas dan Angkutan Jalan.Penerbit ITB. 